\title{
Brief Distress Screening in Clinical Practice: Does it Help to Effectively Allocate Psycho-Oncological Support to Female Cancer Inpatients?
}

\author{
Kerstin Hermelink Henrik Höhn Stephan Hasmüller Julia Gallwas \\ Kristin Härtl Rachel Würstlein Janna Köhm \\ Department of Gynaecology and Obstetrics and Comprehensive Cancer Center, Ludwig Maximilian University, Munich, Germany
}

\section{Keywords}

Distress screening - Psychosocial distress · Distress Thermometer · Psycho-Oncology · Counselling

\section{Summary}

Background: The usefulness of distress screening in cancer inpatient settings has rarely been investigated. This study evaluated a brief distress screening of inpatients in a breast cancer centre and a gynaecological cancer centre. Patients and Methods: Hospitalised patients with breast or gynaecological cancers were screened with the Distress Thermometer. Patients who scored above the cut-off, were referred by the medical staff, or selfreferred were offered bedside psycho-oncological counselling. Results: Of 125 patients, 68 (54.4\%) received an offer of counselling, and 62 patients (49.6\%) accepted. Most of the counselling was induced by distress screening. Only $4(3.2 \%)$ patients self-referred to the counselling service. Of the counselled patients, $65.8 \%$ stated that they had substantially benefited from psycho-oncological support; only $5.6 \%$ of the non-counselled patients indicated that they might have benefited from psychooncological support. Conclusion: Almost all patients who will accept and benefit from psycho-oncological counselling can be identified if distress screening is used in conjunction with referrals by physicians and nurses. Distress screening is a worthwhile component in a framework of psycho-oncological support in a cancer inpatient setting. It paves the way to counselling for cancer inpatients who need it and are willing to accept it but hesitate to selfrefer to psycho-oncological services.

\section{Introduction}

There is no doubt that cancer and cancer therapy can impose an immense psychological burden on affected individuals. The severe emotional distress many cancer patients suffer often remains unnoticed and thus untreated [1]. Screening for distress has therefore been recognized as an important issue in oncology care [2]. While a growing body of research has investigated the impact of distress screening in cancer outpatient settings [3-8], research on distress screening in cancer inpatients has only just begun. Evidence of particularly high levels of emotional distress $[9,10]$ and high rates of mental disorders [11] in hospitalised cancer patients suggests that distress screening may be especially relevant in an inpatient setting. In an Australian study, distress screening increased inpatient referrals to psychosocial services [12].

Screening is not necessarily useful, even if valid screening tools are used [13]. Patients who are correctly identified as highly distressed may still not get help, and even if psychological support is available for these patients, they may not accept it [3]. Conversely, less distressed patients may want psychological support $[6,14]$ and benefit from it as a preventative measure. Distress and acceptance of psychological support have been found to be modestly $[13,15-18]$ or not at all $[3,6$, 19] correlated. For this reason, we did not intend to validate a screening instrument against a more elaborate measurement of psychological state but to explore whether a brief, easily feasible screening is useful in clinical practice. Taking into account the fact that in practice, screening is never the only pathway to psycho-oncological counselling, we deliberated that distress screening should be considered useful if the following criteria were met: i) a combination of referrals from the medical staff, patient self-referrals, and distress screening should identify almost all patients who accept counselling and benefit from it; ii) a substantial proportion of these patients should be identified exclusively by distress screening; and iii) distress screening should not induce counselling in a

\section{KARGER}

Fax +497614520714

Information@Karger.com

www.karger.com (c) 2014 S. Karger GmbH, Freiburg

$1661-3791 / 14 / 0092-0129 \$ 39.50 / 0$

Accessible online at:

www.karger.com/brc
Dr. Kerstin Hermelink

Klinik und Poliklinik für Frauenheilkunde und Geburtshilfe

Universität München

Marchioninistraße 15, 81377 München, Germany

kerstin.hermelink@med.uni-muenchen.de 
substantial number of patients who do not benefit from it Further, we wanted to explore how many patients are selected for psycho-oncological counselling if distress screening is used, and how many of these patients accept counselling and receive it. We investigated these questions in the breast cancer centre and the gynaecological cancer centre of our university hospital. In both centres, screening with the Distress Thermometer is a long-standing clinical routine.

\section{Patients and Methods}

All patients passed through the usual screening and counselling routines established in our hospital. Patient data und data on screening and counselling were routinely recorded. Shortly before discharge, an assessment of eligible patients was added for the study (fig. 1). The assessment included a brief interview to determine actual benefit in patients who had received counselling, and potential benefit from counselling in those who had not received it. Actual benefit and potential benefit from counselling were conceptualised as patient-perceived actual benefit and patient-presumed potential benefit, respectively. We were confident that counselled patients could best appraise actual benefit themselves. Even though the non-counselled patients' expectations of counselling benefits may be less correct, it is unlikely that patients who do not expect to benefit from counselling would even have accepted it. To complement the patients' appraisals, we additionally assessed the course of distress and emotional state at discharge. We then determined whether patients who potentially could have benefited from counselling had been overlooked in spite of screening. We further determined how many patients had received counselling exclusively because of screening - without a referral or self-referral - and benefited from it, and how many patients had been counselled without benefit.

\section{Procedure}

Following our clinical routine, all patients were handed the Distress Thermometer upon admission by a nurse. To not increase the nurses' workload, return of the filled-in Distress Thermometer forms was left up to the patients. The forms were then forwarded to 2 onsite clinical psychologists who personally offered psycho-oncological counselling to all patients who scored 5 or more on the 0-10-point Distress Thermometer analogue scale or indicated 2 or more of 5 emotional problems (worry, fears, sadness, depression, and nervousness) on the adjunct problem list. These cut-off scores were chosen based on reported observations in German cancer patients [20]. In addition to screening, physicians and nurses referred patients in need of counselling to the psychologists, and the patients were made aware of the opportunity to self-refer to the counselling service. Counselling differed in number and length of sessions and included psycho-educational and supportive elements according to the patients' individual needs. Counselling was either covered by insurance or free. Whenever a clinician who was involved with the study was available at the time of a patient's discharge, this patient, if eligible, was asked to participate in a brief assessment.

\section{Assessments}

The Distress Thermometer, a widely-used and well-validated selfreport screening tool $[2,16,18,20-26]$, consists of 2 sections, the 11-point distress scale featured as a thermometer, and the Problem List that specifies potential sources of distress. Distress Thermometer screening results, offers of counselling, acceptance of counselling, length of counselling sessions (for descriptive purposes), the pathway that had induced counselling, and basic demographic and medical data were recorded for all patients (fig. 1). Additional demographic data were collected at the assessment before discharge. The Distress Thermometer was applied again. The Hospital Anxiety and Depression Scale (HADS) [27], a wellestablished 14-item questionnaire created to measure depression and anxiety in somatically ill patients, was administered. Additionally, counselled patients, i.e. patients who had received at least $10 \mathrm{~min}$ of counselling, were asked whether the counselling had been dispensable, rather less important, important, or very important to them. The patients who rated the counselling as important or very important were considered to

Entire Sample: $\mathbf{n}=\mathbf{1 2 5}$

- Breast cancer or gynaecological cancer

$\circ \quad \geq 2$ nights in hospital

- Screening and counselling routines as established -

Data collection:

- Basic demographic and medical data

- Distress Thermometer at admission (screening)

- Counselling offered yes/no

- Counselling accepted and received yes/no

- Length of counselling, total of all sessions

- Pathway to counselling (screening, referrals,

self-referrals, and/or miscellaneous causes)

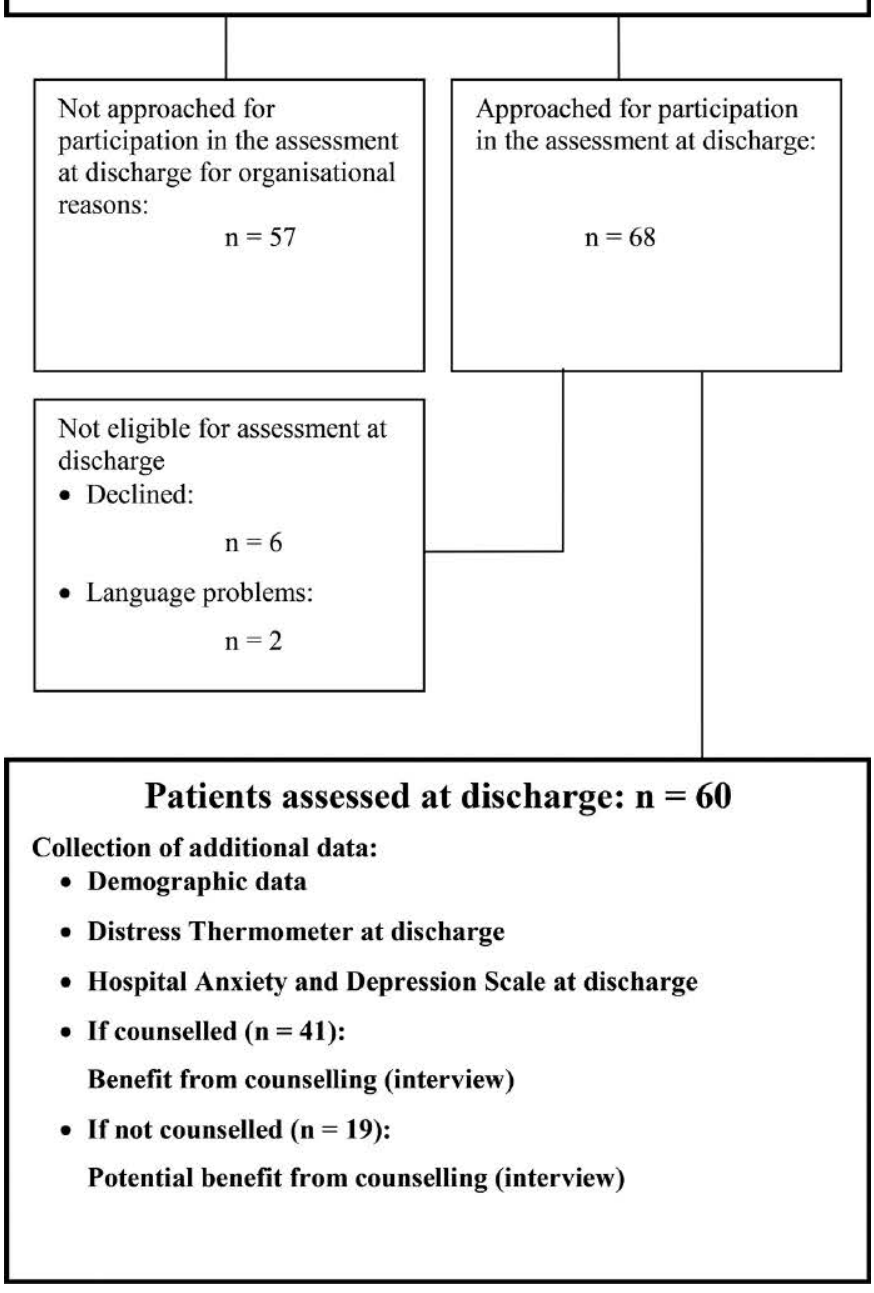

Fig. 1. Flow chart of study proceedings. 
have benefited from the counselling. Non-counselled patients were asked whether they thought that psychological support would have been dispensable, rather less important, important, or very important to them. Patients who rated counselling as important or very important were considered to potentially have benefited from it. These patients were asked whether they had known about the opportunity to self-refer to the counselling service, and if they answered in the affirmative, they were asked why they had not made use of it. The assessments were conducted by 1 of 3 physicians, 2 clinical psychologists, or a psychology student. To avoid response bias, none of the patients were assessed by the psychologist who had counselled her.

\section{Patients}

All patients who had been treated for breast cancer or for invasive gynaecological cancers of any stage during a specified period of 15 weeks and had stayed for at least 2 nights at the Munich University Hospital (Campus Grosshadern) were included. To be further eligible for assessment at discharge, patients needed to speak sufficient German or English and give written informed consent. The study was approved by the ethics committee of the University of Munich.

\section{Statistical Analyses}

T-tests and chi-square tests were used. All analyses were carried out with the Statistical Package for the Social Sciences, SPSS versions 19 and 20 (IBM Corp., Armonk, NY, USA). Statistical tests were 2-sided, and significance was calculated with a $5 \%$ type I error.

\section{Results}

During the specified period, 125 cancer patients (breast cancer $\mathrm{n}=71$, gynaecological cancer $\mathrm{n}=54$ ) had stayed at least 2 nights at the hospital. The data of these patients were included in the analysis (fig. 1). 69 (55.2\%) patients had at least partially filled in the Distress Thermometer and returned it. Of all 125 patients, 68 (54.4\%) were offered counselling, and 62 accepted the offer and received counselling (91.2\% of the approached patients and $49.6 \%$ of all patients). None of these rates differed significantly between breast cancer patients and patients with gynaecological cancers. Of the patients who received counselling, 24 had been referred by physicians or nurses, 4 had self-referred, 10 were counselled for miscellaneous causes (they had already been known to the counsellors, the counsellors were alerted by fellow patients, or the counsellors had accidentally noticed the patient's need of counselling), and 43 were identified by screening. Counselling could be induced by more than 1 pathway, and these groups therefore overlap. 30 patients were not referred or otherwise selected for counselling but were counselled exclusively because of screening (48.4\% of all counselling cases and $24.0 \%$ of all patients). 68 patients were invited to be assessed shortly before discharge. Of these, 6 declined, 2 had language problems, and 60 participated in the assessment. Patients who were assessed at the time of discharge did not differ significantly from non-assessed patients regarding age, diagnosis, length of hospital stay, Distress Thermometer score at admission, and number of emotional problems at admission. More assessed than non-assessed patients had received personal offers of counselling and had been counselled (table 1).

Table 1. Patient characteristics, and screening and counselling statistics

\begin{tabular}{|c|c|c|c|c|}
\hline & $\begin{array}{l}\text { All patients } \\
(\mathrm{n}=125)\end{array}$ & $\begin{array}{l}\text { Patients assessed } \\
\text { at discharge }(\mathrm{n}=60)\end{array}$ & $\begin{array}{l}\text { Patients not assessed } \\
\text { at discharge }(n=65)\end{array}$ & $\mathrm{p}$ \\
\hline Age, mean (SD), years & $60.4(12.8)$ & $59.4(12.6)$ & $61.4(12.9)$ & 0.391 \\
\hline Relationship status, $\mathrm{n}(\%)$ & & & & - \\
\hline In domestic partnership & - & $41(68.3)$ & - & \\
\hline Single & - & $19(31.7)$ & - & \\
\hline Educational level, n (\%) & & & & - \\
\hline Low & - & $18(30.0)$ & - & \\
\hline Medium & - & $21(35.0)$ & - & \\
\hline High & - & $21(35.0)$ & - & \\
\hline Diagnosis, n (\%) & & & & 0.696 \\
\hline Breast cancer & $71(56.8)$ & $33(55.0)$ & $38(58.5)$ & \\
\hline Gynaecological cancer & $54(43.2)$ & $27(45.0)$ & $27(41.5)$ & \\
\hline Length of hospital stay, mean (SD), days & $7.8(5.9)$ & $8.0(5.0)$ & $7.7(6.7)$ & 0.741 \\
\hline Distress Thermometer score at admission, mean (SD) & $\begin{array}{l}5.7(2.8) \\
\mathrm{n}=62\end{array}$ & $\begin{array}{l}6.0(2.8) \\
\mathrm{n}=36\end{array}$ & $\begin{array}{l}5.3(2.7) \\
\mathrm{n}=26\end{array}$ & 0.371 \\
\hline $\begin{array}{l}\text { Emotional problems indicated on Distress Thermometer } \\
\text { at admission, mean (SD), } \mathrm{n}\end{array}$ & $\begin{array}{l}1.9(1.7) \\
\mathrm{n}=69\end{array}$ & $\begin{array}{l}2.3(1.6) \\
\mathrm{n}=40\end{array}$ & $\begin{array}{l}1.5(1.8) \\
\mathrm{n}=29\end{array}$ & 0.068 \\
\hline Counselling offered, $\mathrm{n}(\%)$ & $68(54.4)$ & $44(73.3)$ & $24(36.9)$ & 0.001 \\
\hline Counselling received, $\mathrm{n}(\%)$ & $62(49.6)$ & $41(68.3)$ & $21(32.3)$ & 0.001 \\
\hline Counselling time per counselled patient (total of all sessions), $\mathrm{n}(\%)$ & & & & 0.347 \\
\hline $10-30 \mathrm{~min}$ & $20(32.8)$ & $14(35.0)$ & $6(28.6)$ & \\
\hline $31-60 \mathrm{~min}$ & $21(34.4)$ & $15(37.5)$ & $6(28.6)$ & \\
\hline $60-90 \mathrm{~min}$ & $11(18.0)$ & $6(15.0)$ & $5(23.8)$ & \\
\hline $90-120 \mathrm{~min}$ & $5(8.2)$ & $4(10.0)$ & $1(4.8)$ & \\
\hline$>120 \mathrm{~min}$ & $4(6.6)$ & $1(2.5)$ & $3(14.3)$ & \\
\hline
\end{tabular}

$\mathrm{SD}=$ Standard deviation 


\section{Counselled Patients: Assessment of Benefit from Counselling}

Of the 41 counselled patients who were asked how important psycho-oncological counselling had been to them, the answers of 3 patients could not be coded. Of the remaining 38 patients, $25(65.8 \%)$ stated that the psychological support had been important $(n=15)$ or very important $(n=10)$ to them. $11(44 \%)$ of these patients had been detected exclusively by screening. $13(34.2 \%)$ patients rated the psychological support as less important $(\mathrm{n}=8)$ or dispensable $(\mathrm{n}=5)$. Comparison of Distress Thermometer scores at admission (mean 6.6, standard deviation (SD) 2.6, $\mathrm{n}=30$ ) and at discharge (mean 4.7, $\mathrm{SD} 2.8, \mathrm{n}=38$ ) showed a significant reduction in distress in counselled patients (paired t-test: $\mathrm{p}=0.014, \mathrm{n}=28$ ). The mean HADS score of counselled patients at discharge was $13.2(\mathrm{SD} 7.2, \mathrm{n}=39)$.

\section{Non-Counselled Patients: Assessment of Potential Benefit from Counselling}

Of the 19 non-counselled patients who were asked whether psycho-oncological counselling might have been important, 1 patient could not decide; of the 18 remaining patients, 17 $(94.4 \%)$ rated counselling either as dispensable $(\mathrm{n}=10)$ or as less important $(\mathrm{n}=7)$, and 1 patient said that counselling would have been important to her. She stated that she had known of the opportunity to self-refer to the counselling service but had been too busy to use it. No reduction in distress was observed in the non-counselled patients (Distress Thermometer score at admission, mean 3.0, SD 1.8, $\mathrm{n}=6$; at discharge, mean 3.6, SD 2.2, $\mathrm{n}=17$ ). Non-counselled patients scored significantly lower in the HADS at discharge (mean 7.6, SD 5.4, $\mathrm{n}=18$ ) than counselled patients (see above; $\mathrm{p}=0.005)$.

\section{Discussion}

We evaluated the usefulness of distress screening under practice conditions in an inpatient setting. To obtain a truthful picture, the patients underwent the usual screening and counselling routines that are established in our hospital. About half of all patients who stayed at our centres for breast and gynaecological cancers for at least 2 nights received personal offers of bedside psycho-oncological counselling. Offers were accepted by more than $90 \%$ of the approached patients, a rate that far exceeds acceptance rates observed in outpatient samples [3-6, 16, 28]. There may be several reasons for this divergence: hospitalised cancer patients have been found to suffer from particularly severe distress $[9,10]$; bedside counselling means less expenditure of time and effort than appointments at external psycho-oncology services, a point that may be particularly relevant for cancer patients many of whom are frail; and moreover, personal invitations by the counsellors themselves may lower the threshold for counselling.
Even though only little more than half of the patients had participated in the distress screening, most counselling was prompted by screening. Almost half of the counselled patients had not been referred by the medical staff but were offered counselling based exclusively on distress screening. Very few patients self-referred. Evidently, the patients preferred to communicate their counselling needs through the screening instrument and to be subsequently approached by a counsellor.

Two-thirds of the counselled patients reported considerable benefit from the psycho-oncological support. The lack of substantial benefit from counselling that was reported by the remaining third of counselled patients may be partially due to the failure of screening and partially to unsuccessful counselling. Overall, counselled patients showed reduced distress at discharge, which was not observed in the non-counselled patients.

Very few patients who could have benefited from counselling had been overlooked. Only 1 of 19 non-counselled patients who were assessed at discharge declared that counselling might have been important. The non-counselled patients' view that counselling had not been necessary for them was corroborated by the finding that these patients' emotional state at discharge was significantly better than that of counselled patients. Initially low distress levels in this group had only minimally risen. The non-counselled patients had obviously fared well without counselling.

Because of the high rate of patients who benefited from counselling but would have been missed without screening, distress screening for hospitalised cancer patients must be recommended. Obviously, screening gives patients the chance to communicate their emotional state without having to openly admit their need of psycho-oncological counselling. Distress screening thus lowers the threshold to counselling.

Our study has several limitations. In this unfunded investigation, benefit and potential benefit from counselling and thus, implicitly, benefit from screening could only be assessed in a subgroup of patients that was small $(n=60)$, albeit not different from the entire patient sample regarding basic demographic and medical characteristics. Moreover, because data were collected under practice conditions, many data on the patients' distress at admission to hospital are missing. In particular, many patients who regarded counselling as not important chose not to return the Distress Thermometer, and, accordingly, most of these patients did not receive counselling. The finding that the non-counselled patients had low distress levels at admission has therefore to be regarded as tentative. These patients, however, clearly showed low distress at discharge, which confirms that they had not needed counselling. Further, benefit from counselling was largely determined by the patients' subjective appraisals. The results of our study are only applicable if a qualified psycho-oncological service can promptly provide counselling to patients with positive screening results. 
Our study demonstrated that nearly all hospitalised patients with breast or gynaecological cancers, who potentially benefit from psycho-oncological counselling, can be identified if a brief distress screening is used in combination with nurses' and physicians' observations of the patients' needs. If positive screening results are followed up by personal offers of counselling from the counsellors themselves, screening paves the way to psycho-oncological support for many cancer inpatients who refrain from self-referral but still want counselling and benefit from it. Distress screening gives these patients the opportunity to noncommittally communicate their counselling needs. Brief distress screening can be integrated into the clini- cal work at no costs and with minimal effort for staff and patients. However, there is a downside to distress screening: a minority of patients with positive screening results will accept counselling but not benefit from it. We doubt that more valid screening can resolve this issue. Counsellors should be aware that a proportion of patients does not benefit from counselling notwithstanding positive screening results.

\section{Disclosure Statement}

The authors declare no conflict of interest.

\section{References}

1 Carlson LE, Angen M, Cullum J, Goodey E, Koopmans J, Lamont L, MacRae JH, Martin M, Pelletier G, Robinson J, et al.: High levels of untreated distress and fatigue in cancer patients. Br J Cancer 2004;90:2297-2304.

2 Carlson LE, Bultz BD: Cancer distress screening. Needs, models, and methods. J Psychosom Res 2003;55:403-409.

-3 Lynch J, Goodhart F, Saunders Y, O'Connor SJ Screening for psychological distress in patients with lung cancer: results of a clinical audit evaluating the use of the patient Distress Thermometer. Support Care Cancer 2010;19:193-202.

$\checkmark 4$ Carlson LE, Groff SL, Maciejewski O, Bultz BD: Screening for distress in lung and breast cancer outpatients: a randomized controlled trial. J Clin Oncol 2011;28:4884-4891.

5 McLachlan SA, Allenby A, Matthews J, Wirth A, Kissane D, Bishop M, Beresford J, Zalcberg J: Randomized trial of coordinated psychosocial interventions based on patient self-assessments versus standard care to improve the psychosocial functioning of patients with cancer. J Clin Oncol 2001;19:4117-4125.

6 Sollner W, Maislinger S, Konig A, Devries A, Lukas P: Providing psychosocial support for breast cancer patients based on screening for distress within a consultation-liaison service. Psychooncology 2004;13:893-897.

7 Thewes B, Butow P, Stuart-Harris R; Greater Southern Area Health Service Screening Collaborative G: Does routine psychological screening of newly diagnosed rural cancer patients lead to better patient outcomes? Results of a pilot study. Aust J Rural Health 2009;17:298-304.

8 Bidstrup PE, Johansen C, Mitchell AJ: Screening for cancer-related distress: summary of evidence from tools to programmes. Acta Oncol 2011;50: 194-204.

-9 Clark PG, Rochon E, Brethwaite D, Edmiston KK: Screening for psychological and physical distress in a cancer inpatient treatment setting: a pilot study. Psychooncology 2011;20:664-668.

10 Singer S, Gotze H, Mobius C, Witzigmann H, Kortmann RD, Lehmann A, Hockel M, Schwarz R, Hauss J: Quality of care and emotional support from the inpatient cancer patient's perspective. Langenbecks Arch Surg 2009;394:723-731.

11 Singer S, Kuhnt S, Gotze H, Hauss J, Hinz A, Liebmann A, Krauss O, Lehmann A, Schwarz R: Hospital anxiety and depression scale cutoff scores for cancer patients in acute care. Br J Cancer 2009; 100:908-912.

12 Lee SJ, Katona LJ, De Bono SE, Lewis KL: Routine screening for psychological distress on an Australian inpatient haematology and oncology ward: impact on use of psychosocial services. Med J Aust 2010;193:S74-78.

13 Van Scheppingen C, Schroevers MJ, Smink A, van der Linden YM, Mul VE, Langendijk JA, Coyne JC, Sanderman R: Does screening for distress efficiently uncover meetable unmet needs in cancer patients? Psychooncology 2011;20:655-663.

14 Nekolaichuk CL, Cumming C, Turner J, Yushchyshyn A, Sela R: Referral patterns and psychosocial distress in cancer patients accessing a psychooncology counseling service. Psychooncology 2011;20:326-332.

15 Baker-Glenn EA, Park B, Granger L, Symonds P, Mitchell AJ: Desire for psychological support in cancer patients with depression or distress: validation of a simple help question. Psychooncology 2011;20:525-531.

16 Tuinman MA, Gazendam-Donofrio SM, HoekstraWeebers JE: Screening and referral for psychosocial distress in oncologic practice: use of the Distress Thermometer. Cancer 2008;113:870-878.

17 Schaffeler N, Enck P, Riessen I, Seitz D, Marme A, Wallwiener D, Zipfel S: (Screening for mental stress and the wish for psychological support in patients with breast cancer). Z Psychosom Med Psychother 2011;56:207-219.

18 Bidstrup PE, Mertz BG, Dalton SO, Deltour I, Kroman N, Kehlet H, Rottmann N, Gartner R, Mitchell AJ, Johansen C: Accuracy of the Danish version of the 'distress thermometer'. Psychooncology 2012;21:436-443.

19 Merckaert I, Libert Y, Messin S, Milani M, Slachmuylder JL, Razavi D: Cancer patients' desire for psychological support: prevalence and implications for screening patients' psychological needs. Psychooncology 2010;19:141-149.
20 Mehnert A, Müller D, Lehmann C, Koch U: Die deutsche Version des NCCN Distress-Thermometers. Empirische Prüfung eines ScreeningInstruments zur Erfassung psychosozialer Belastung bei Krebspatienten. Z Psychiatr Psychol Psychother 2006;54:213-223.

21 NCCN: Distress management. Clinical practice guidelines. J Natl Compr Canc Netw 2003;1:344 374.

22 Hegel MT, Collins ED, Kearing S, Gillock KL, Moore CP, Ahles TA: Sensitivity and specificity of the Distress Thermometer for depression in newly diagnosed breast cancer patients. Psychooncology 2008;17:556-560.

23 Mitchell AJ: Pooled results from 38 analyses of the accuracy of distress thermometer and other ultrashort methods of detecting cancer-related mood disorders. J Clin Oncol 2007;25:4670-4681.

24 Jacobsen PB, Donovan KA, Trask PC, Fleishman SB, Zabora J, Baker F, Holland JC: Screening for psychologic distress in ambulatory cancer patients. Cancer 2005;103:1494-1502.

25 Gessler S, Low J, Daniells E, Williams R, Brough V, Tookman A, Jones L: Screening for distress in cancer patients: is the distress thermometer a valid measure in the UK and does it measure change over time? A prospective validation study. Psychooncology 2008;17:538-547.

26 Grassi L, Sabato S, Rossi E, Marmai L, Biancosino B: Affective syndromes and their screening in cancer patients with early and stable disease: Italian ICD-10 data and performance of the Distress Thermometer from the Southern European Psycho-Oncology Study (SEPOS). J Affect Disord 2009;114:193-199.

27 Herrmann C, Buss U, Snaith RP: HADS-D. Hospital Anxiety and Depression Scale - Deutsche Version. 1st ed. Bern Göttingen Toronto Seattle, Verlag Hans Huber, 1995.

28 Grassi L, Rossi E, Caruso R, Nanni MG, Pedrazzi S, Sofritti S, Sabato S: Educational intervention in cancer outpatient clinics on routine screening for emotional distress: an observational study. Psychooncology 2011;20:669-674. 